\title{
Epistemic modesty, ostentatiousness and the uncertainties of epigenetics: on the knowledge machinery of (social) science
}

\section{Martyn Pickersgill}

\begin{abstract}
Epigenetic processes are garnering attention in the social sciences, where some scholars assert their importance for theorizing social life. I engage with such ideas here by drawing on interviews with leading bioscientists. To begin with, I underscore the (productive) uncertainties of those working in and around epigenetics; I describe these as a manifestation of 'epistemic modesty', and suggest that dissensus helps to propel biomedical innovation. Then, drawing on the concept of 'alien science', I detail some researchers' ambivalences regarding the notion of 'transgenerational inheritance'; their dissatisfaction with the (public) communication practices of other scientists (situated in what I term a regime of 'epistemic ostentatiousness'); and the challenges faced when moderating societal discussion of epigenetics in ways that expand excitement whilst deflating (what researchers regard as) unrealistic expectations. The paper concludes with reflections on the knowledge machinery of the (social) sciences, and employs the study data to interrogate sociological engagements with epigenetics.
\end{abstract}

Keywords: epigenetics, transgenerational inheritance, public engagement, alien science, collaboration, knowledge machinery, epistemic modesty

\section{Introduction}

At a cultural moment when many scientists are rehearsing concerns about the fragmentation of disciplines and over-specialization, epigenetics - as an idea, an approach, and maybe a field - has come to be seen by a range scholars as having the potential to cast a bright light upon the ontogenies and ontologies of human being(s). In particular, some argue that this will be through novel rapprochements between disciplines. As biologists Patrick McGowan and Moshe Szyf argue:

Epigenetics could serve as a bridge between the social sciences and the biological sciences, allowing a truly integrated understanding of human health and behaviour. (McGowan and Szyf, 2010: 71) 
Social scientists too have been participants in conversations about the implications of epigenetics, including for their own knowledge machinery. As Nikolas Rose has observed, '[n]o longer are social theories thought progressive by virtue of their distance from the biological' (Rose, 2013: 4). Perspectives on this assertion would, of course, vary depending on which (sub)discipline of the social sciences one happened to be considering. Yet, the corridor talk, blog discussions and conference presentations that have played out in recent years are certainly suggestive of an expectation - or, perhaps more accurately, an enthusiasm (cf. Will, 2010) - that the choreography of sociological theory should involve at least some dancing with biology. In the case of epigenetics specifically, Nicolosi and Ruivenkamp, for example, conclude that this 'could be a new paradigm' with the potential to 'support humanities [scholars] and social scientists in their analyses and interventions' (Nicolosi and Ruivenkamp, 2012: 318). While the possibility of 'experimental entanglements' (Fitzgerald and Callard, 2014) between sociologists and biologists is compelling, discussions nevertheless sometimes elide scientific uncertainties around epigenetics - and, hence, what collaboration might look like in practice, and what it might achieve.

This paper engages with this elision by drawing on semi-structured interviews conducted as part of a Wellcome Trust-funded study concerned with how notions of 'responsibility' were being configured within epigenetics. Through this research, I wanted to understand how leading scientists were being enjoined to engage with policymakers and publics and reflect on the implications of their research, the forms that this took, and how this in turn shaped their sense of 'responsibility' (to their discipline, their colleagues, and to wider publics) - as well as what kinds of 'responsibilities' findings from epigenetics itself might imply for institutions and citizens. However, in spite of the growing visibility of research on epigenetic processes, as the interviews commenced it soon became clear that my respondents' experiences of policy and public engagement were not extensive, and their thoughts on the robustness of extant research were cautionary. Whilst rich data around responsibility (in its various forms) was certainly produced through the interviews, another issue emerged that first demanded close attention and consideration. To put it plainly: was 'epigenetics' even a thing from which implications could develop?

It is this question, then, that forms the starting point for my analysis. In what follows, I document some of the uncertainties and variance encountered in my interviews (and elsewhere), before moving on to discuss how the scientists I spoke with configured these as relevant to wider public engagement. I conclude with considerations of how my data underscores the centrality of regimes (cf. Moreira and Palladino, 2005) of 'epistemic modesty' (Will, 2010) and what I term 'epistemic ostentatiousness' to the knowledge machinery (Moreira et al., 2009) of the biosciences. I note how some research in epigenetics can be configured as a kind of 'alien science' (Collins, 1999; Hedgecoe, 2006), and reflect on the implications of this for the workings of the social sciences. 


\section{Methods}

This paper draws upon, as its primary data, interviews with leading UK researchers working in areas defined by themselves or other influential actors as pertaining to epigenetics. It is further informed by conversations with other scientists in the UK and North America, and ongoing examination of editorials, reviews and correspondence around epigenetics published in major journals.

Participants were contacted via targeted emails, after being identified through their authorship of highly cited articles, presence on relevant Editorial Boards, and receipt of major grants relating to epigenetics, methylation or chromatin. The interview sample was restricted to senior scientists in major institutions in order to include only respondents who could reasonably be expected to provide perspectives on how their field had developed, critical reflections on the work currently gaining attention within it, and deliberate thoughtfully on the ethical and social implications of research termed 'epigenetics'. This sampling strategy produced a reasonably small population of potential respondents, and ten interviews in total were conducted with full professors across five research-orientated universities. ${ }^{1}$

Interviews were semi-structured, moving in different ways (and to varying extents) across a topic guide that included questions and prompts pertaining to: (1) definitional and epistemic issues in epigenetics (including what the word was taken to mean, and the respondents' views on debates around 'transgenerational inheritance'); (2) scientists' experiences of public and policy engagement (for instance, whether the interviewees had participated in any public events, what their contributions to those had been, and what had initiated their involvement); and (3) the societal and ethical implications of the respondents' own and others' research (eg, if and how organizations like the Nuffield Council on Bioethics should respond to epigenetics, and what kind of emergent issues bioethicists ought to address). Interview encounters (ie, total length of time spent discussing issues with participants) lasted between 30 minutes and just over one hour. ${ }^{2}$ Interviews were recorded, transcribed and analysed thematically.

\section{What is epigenetics?}

Struck by the variety of position pieces on epigenetics in the scientific literature (Pickersgill et al., 2013), in most of my interviews I asked: what does the term 'epigenetics' mean to you? Responses - unsurprisingly, given the debates within the journals - were varied, and some participants reflexively listed the different definitions available. As Respondent 8 answered:

So, epigenetics to me means three sorts of things really. The first one is Waddington's definition, how the genotype gives rise to the phenotype, and [...] that's now called developmental biology really. There's the heritability one, which is the most popular, I would say, which is the idea that it's inheritance of erm characteristics in a quasigenetic manner, but without any genetic changes. And the third use of it is as the study 
of the epigenome. So the epigenome being all of the bells, and whistles, and chemical modifications attached to DNA, but with an honorary place for RNA as well, so that's a much more molecular definition. And the reason why I separate that from the second one, is that many of these, most of these marks have not been shown to be heritable. So there's no obligatory heritability about them. So those are the three usages. But the one that is attracting most attention is the middle one. The one about heritable changes. ${ }^{3}$

Respondent 9 likewise cited Waddington (the developmental biologist usually credited with coining the term 'epigenetics' in the 1940s), before moving on to discuss broader understandings of epigenetics:

Well, it depends on whether I'm thinking rigorously or thinking sloppily so thinking rigorously, I would use Waddington's definition which is it's a trait which is inherited but which is apparently not encoded in the DNA. Er, now people use the term epigenetic to refer to almost any modification of a histone protein and chromatin, and certain modifications of the DNA. Whether they are truly epigenetic is another issue, so if you modify the histones in a particular way to make the chromatin in a particular region silent, is that actually inherited? Well, sometimes yes, and sometimes no, so, but people are quite happy to use the term because I think it sounds sexy, so they like it.

Respondents 2, 6 and 10 similarly located their definitions in terms of inheritance: 'the most important aspect of epigenetics is that it's somatically inherited. That is the key thing' (Respondent 2); and, 'from my point of view, the most important thing about epigenetics is it has to be heritable' (Respondent 6).

Respondent 7 also emphasized heritability, stating that he 'accept[s] the strict definition that some epigenetic information is information which is heritable either through cells or generations, and not directly coded in the DNA'. However, at the same time as he thought 'people should always keep that in mind as the strict definition', he was prepared to expand this in order to accommodate his own interests. In so doing, he could go about his research unhampered by some of the more profound ontological debate that appeared to be shaping and directing the work of other participants:

I don't probably use [the term epigenetics] in the way that a lot of people in the field say it should be used. I mean, people are quite semantic about it. Erm, I tend to use it quite loosely, partly because you know you've got a choice of saying you work on epigenetics or chromatin. You know, one of them tends to get people excited. The other one tends to turn people off a bit. So, so I use epigenetics, but erm I don't worry too much about all this, you know, 'to be epigenetic it has to be heritable' business. I mean, I can see why people, I can see why people want to define it that way. But I think it's okay to use it more loosely provided you know what you're talking about.

Likewise, Respondent 5 was 'very happy with the breadth of the way [the term epigenetics is] now used. I think that's entirely right'. He maintained that 'the important thing is to get across this fundamental message that-that-that genes do what they're told. And epigenetics is-is the process by which genes are told what to do.' As we will later see, some of the scientists interviewed were troubled by this message when it was circulated within the public sphere. Further, it is precisely a 'loose' or 'broad' use of the term epigenetics that can sometimes be regarded as 
problematic for knowledge-production and the clarification of complex biological processes, as this exchange with Respondent 3 underscores:

Respondent $3:[\ldots]$ the term 'epigenetic' has changed a lot in the last er, in the last year.

Martyn: Yeah, I've noticed that.

Respondent 3: So originally we called epigenetics the methylation of the DNA, and then people put the acetylation of the protein, the histone, that was a kind of classic, but today they call epigenetics every change in the expression of the gene, er which is not due to a change in the nucleotide, in the DNA. And with all the work from ENGAGE [a large European Commission project on genetic epidemiology] and the others, now they considered that the non-coding RNA of different species of that, microRNA, circular RNA, blah blah blah. All this non-coding RNA, as it modifies the expression can be considered as epigenetic factors. So we are in the situation where the term epigenetics er means [things that are] extremely different for people. Er and in my view the term is er, is probably wrong today. Because all the people who are working on non-coding RNAs, say now that they do epigenetics. So it's a problem.

Respondent 6 was particularly critical of some of the research that today was referred to as 'epigenetics', deeming some of it 'intellectually lazy'. As he reflected: 'I think most people claiming to work in epigenetics are not epigeneticists and haven't a clue how it works or how it doesn't work'. Seeming to gesture to the work of Michael Meaney and Moshe Szyf at McGill University (Weaver et al., 2004) - which is especially visible in wider commentaries on epigenetics - he asserted:

You have the science, which I really hate, where allegedly you rub the head of a pup and you change its epigenetic profile. It's nonsense. I mean if there's something physiological going on it's not because of the epigenetics it's the epigenetics are a reflection of that[.]

Respondent 8 was likewise critical of some of Meaney and Szyf's studies on pup licking behaviour and the brains of individuals who had committed suicide (eg Weaver et al., 2004; McGowan et al., 2009). These were discussed in strong words, with the data from the former study described as 'weak' and '[s]uspect', and the latter 'massively underpowered' and 'unacceptable'. Respondent 8 was 'happy to believe that early experiences are important', but 'not happy to believe that there's any evidence that this is mediated by DNA methylation or other epigenetic marks'.

Nevertheless, in spite of the potential problems raised by conceptual opacity around the term 'epigenetics', and the prominence of so-called 'weak' science, Respondent 8 still felt that good research could be undertaken:

The point I would make at this-this juncture is that, all of the issues raised by all the different sorts of epigenetics are cutting edge issues. We don't really understand development at the molecular level in any comprehensive way. We, we, there is the possibility that things are inherited, that are not genetic. It's not clear how important this is biologically, but this is an interesting area. And the epigenome, we don't really understand what all those marks and things do, so if you, rather than fighting about which definition you want to support, er I prefer the stance that, all three of them are really 
interesting biologically. All deserve further work and er so however you define it, it's interesting.

Indeed, Respondent 6 - perhaps most caustic of all the interviewees in his views regarding much work termed 'epigenetics' - seemed to suggest that a corollary of a settled definition would be the petering out of research in this area:

I think if we were to stop changing our definitions and finally stick with one, and decide this is it, probably, it would not last because more than likely it's going to fall down to some situation.

More generally, though, a keenness to engage with complexity and uncertainty, and the practices of knowledge-production these conceptual issues propelled, was tangible:

I find the whole field really exciting. You know, we have hundreds, not thousands, hundreds of different epigenetic marks. We don't really know that much about how they work. And I would say, I don't see epigenetics as a separate field. I don't think it's really a subject, actually. You know, biology is a subject, and er I'm interested in how genes are regulated, and epigenetics is a, a branch of that enquiry, if you want to use the word. And many people don't want to use the word, because they feel they're just getting into a quagmire once they do that. So, and I don't use it all that much. (Respondent 8)

In sum, my interviews underscore a range of ontological ambiguities regarding 'epigenetics'. Such ambiguity situates research around epigenetics within a similar epistemological trajectory to that charted by Rheinberger (2010) for genetics (see also Barnes and Dupré, 2008). In particular, Rheinberger argues that conceptual imprecision within science does not necessarily impede epistemic innovation - rather, it can be a powerful engine for research. The interview data suggest the applicability of this contention for studies relating to epigenetics, where the variability of the term constitutes a productive (and for some, exciting) ambiguity enabling different approaches and research questions to proliferate (Lloyd and Raikel, 2014a, 2014b). When Respondent 9 speaks of the 'sexiness' of epigenetics, he intimates one attractant to this area of research, and hence propellant of ambiguity: specifically, the considerable (economic and symbolic) capital accruable for work in this area, and the self-conscious movements by various scientists to situate their investigations in ways that make them eligible for such investments.

\section{Transgenerational inheritance and scientific un/certainty}

In biomedical, social scientific and humanities accounts, the term 'epigenetics' is commonly traced back to the early twentieth century and the British embryologist Conrad Waddington. However, as shown above, the term today is not transparent: it is used ambiguously to refer to a field, a mechanism and an effect and definitions abound. As Respondent 3 reflected, the 'boundary [of epigenetics is] exploding'; consequently, 'we have absolutely no idea what epigenetic means today'. Yet, both formalized and functional definitions are possible - and even 
if their variety contributes to both epistemological disunity within the scientific community and the individualized uncertainty that Respondent 3 underscores, this may itself be productive (cf. Rheinberger, 2010; see also Feyerabend, 2011; Pickersgill, 2014).

The word 'heritable' is frequently deployed within these definitions. Its inclusion is not a requirement, but its import is hard to ignore. The notion that particular biochemical marks may be inherited across organismal (rather than just cell) generations is more radical, however, and has sparked excitement and debate within biomedicine and beyond. What is commonly referred to as 'transgenerational inheritance' has been discussed extensively in recent years. Indeed, one of my interviewees suggested that the editors of key journals have actively cultivated such discussion: 'Nature, Science and Cell, the big three, love it [ie the concept of transgenerational inheritance]. And they solicit papers about that. And they also have er, an affection for any paper that shows that' (Respondent 8).

Given the excitement associated with transgenerational inheritance, in my interviews I sought opportunities to invite reflection on its facticity. ${ }^{4}$ Rather than the enthusiasm that can easily be divined beyond biomedicine, the respondents tended to 'hedge their bets' or were openly critical of the notion of transgenerational inheritance - as well as of studies purporting to evidence it. Even Respondent 4 , who said that 'it is hugely exciting to think that [transgenerational inheritance] might be going on', felt it important 'to look at the evidence very carefully $[\ldots]$ and in a neutral kind of fashion'.

Respondents 5, 9 and 10 were more cautious about the possibilities of transgenerational inheritance; as Respondent 9 put it, 'it definitely can happen, but does it happen on every kind of mark? No, absolutely not.' For Respondent 5:

I mean, can epigenetic characteristics be passed on er from one generation to the next? Well, possibly they can. That's still controversial. I think they probably can, but erm, you know, it's an area that's being researched and has been argued over for probably 200 years, since Lamarck. Erm ... But, it-it will be resolved, but I don't think it's fundamental.

Such caveats and perhaps agnosticism enabled the scientists to go about the business of rigorous knowledge-production in their own specific areas, without grander conceptual questions surrounding the entities under consideration interfering in this (cf. Star, 1985; Pickersgill, 2014).

Respondent 2 was also somewhat agnostic, and appeared to lean towards scepticism about the possibilities of transgenerational inheritance:

I guess if I was to put my cards, you know say which, if I had to jump one way or t'other, because I think it is controversial and I think it's quite uncertain at this stage, and I think there's evidence pro and con. Erm my feeling is against it. So I mean without question there is epigenetic variability between individuals, but whether that's transgenerationally inherited [...] I think the jury's still out. I think there are examples that look as though it could be, but I think they could actually potentially be explained by underlying genetic change that's been meiotically inherited and is then driving it. 
Respondents 6 and 8 were most overtly critical of the idea that transgenerational inheritance could be taken for granted. Throughout the interview, Respondent 6 justified this critique in three different ways. His most pragmatic justification involved implying a lack of reproduction of the studies that claimed to evidence it (a familiar trope within biomedicine). He lamented this, saying 'unfortunately in science, if you publish first that gets embedded, and it's very hard to shift it afterwards. And it's important that you do'. ${ }^{5}$ Respondent 6 also articulated a specifically methodological concern with studies suggesting the possibility of transgenerational inheritance, which rendered their claims problematic. He argued that other scientists' studies on environmental exposures were not persuasive since

the way they've done the experiment was a bit like you know the Russian doll, right? So what you've done is you've taken the female rat whose carrying an embryo and you've exposed it to the drug in utero, which affects both the mother and the pups in utero. But what those pups in utero are also carrying is also the primordial germ cells for the next generation after that. So, you're not only affecting the pups you're actually affecting the germ cells that are going to contribute to the next generation. So, it looks like you're getting a trans-generational effect because the pups affected and when they give birth to their next set they're affected too but in actual fact if you take those and propagate those they don't have it because it stops. Because they weren't exposed and the ones that survive are, obviously, more likely the healthy ones than the other ones.

Finally, Respondent 6 accounted for his scepticism in terms of an evolutionary logic. He could 'see arguments about why' transgenerational inheritance 'would be a very bad thing for an organism'; specifically, if DNA methylation was inherited,

you can imagine if that keeps happening over generations eventually you're going to cumulate methylation everywhere. And you're just going to gum up the organism and it's not going to work anymore. So, that's one very important reason why we have reprogramming between the generations. To reset the, if you like, the modifications so you can start on a new template all over again, that is determined and directed by the genetic programme, genetics, transcription pathways and signalling. So, that would be my view because otherwise I think we end up in a form of Lysenkoism which I think is utter nonsense.

Similar criticisms were advanced by Respondent 8 , who also spoke of evolutionary logics, and felt that 'a lot of the evidence [for transgenerational inheritance] in my opinion is suspect. Partly because the effects are absolutely tiny'. Ultimately, he concluded:

I would like people to get over the transgenerational thing. There are interesting examples as I mentioned, but it's not the be all and end all, and I would like to get mechanistically, a better understanding of how genes are regulated. Because, actually it's all a bit mysterious at the moment and we're making progress but it's, erm, er there are still some big unanswered questions. So I'm excited about the field, but I'm frustrated really by the distraction of some of these other aspects. 
While some evidence that transgenerational inheritance is possible circulates within journals and elsewhere, other commentaries suggest a more cautious appraisal of this notion. ${ }^{6}$ The scientists weighed claims regarding transgenerational inheritance throughout the interviews, largely situating their accounts within a register of 'epistemic modesty' (cf. Will, 2010). In doing so, they contribute to 'deciding the [perceived] character' of biological processes and ontologies (cf. Collins, 1975: 220). Indeed, studies of transgenerational inheritance (and behavioural epigenetics) seemed to appear as 'alien science' (Collins, 1999; Hedgecoe, 2006) to some of the respondents: that is, research that attracted interest and excitement to those conversant with or excited by work in epigenetics, but which was less compelling to senior scientists who had spent many years studying methylation, chromatin biology, and the like. This 'alien science' was concerning to most of the biologists I spoke with once it became taken as simply 'science', and in particular when that was within discursive arenas populated by non-scientific publics. Hence, it is to public engagements with epigenetics that we now turn.

\section{Communicating epigenetics}

Notwithstanding definitional difficulties and uncertainties over the salience of transgenerational inheritance, there are - in Respondent 3's words - also 'a lot of issues, $[\ldots]$ about the interpretation of the results, in epigenetics'. In particular:

if you find an epigenetic signature in people with a disease, it's extremely difficult to decide if this epigenetic signature has something to do with the development of the disease or is a consequence of the disease. Which means that causality is extremely difficult to, to assess in epigenetics. Plus all the problem[s] we have with technical things, which means that most of the work done in epigenetics today were extremely targeted or using genome-wide analysis that were very, very modest. So, the arrays that we use, for instance, analyse only 5 per cent of the, what we call the epigenome.

Respondent 1 also noted the difficulties in parsing causation and correlation in epigenetics, as well as stating that 'people doing non-epigenetic work are very critical of it'. When I asked Respondent 1 what other scientists were critical of, he replied:

In that it is an epiphenomenon. That erm in fact the genes are driving things and it's driven by gene expression, not the other way round, and er it's sort of just reflecting the atmosphere, the environment. Like a bit of litmus paper that's quite useful, but it's not the main driver of what's happening. Erm, and then to, and whilst that should be still great, to the genetics community that's seen as a major negative, because they're very much focused on the genetic point of view. And they see, a lot of genetic people see epigenetics as a threat [due to changing patterns of funding].

On the other hand, Respondent 8 seemed to suggest that there was not enough self-criticism and epistemic modesty on the part of some researchers involved in epigenetics: pointing to what he called 'the evangelical wing of the epigenetics area', he was 'deeply suspicious' of ostentatious presentations of 'the old 
paradigm of genes and genetics' as 'old hat' - in particular, when simultaneously positing as a 'revolution' the notion that 'stuff that happens in the environment can write information, or at least alter information in your epigenome', and is also heritable transgenerationally. Respondent 8 had little time for investigators who undertook public engagement (eg TED talks) 'using their scientific credentials' to articulate implications about epigenetics that he felt were not based on hard science (that, indeed, were 'myths'). He felt that this was 'damaging', and that 'scientists should be the last people who propagate delusion'. Further:

if you were to ask me, what the ethical problems with epigenetics are, I'd say, using rubbish data to influence people's behaviour through pseudo-science. That's would I would say is the big ethical risk of epigenetics. ${ }^{7}$

Though less emotive and less targeted towards other scientists, Respondent 3 also appeared to disdain some of the manifestations of epigenetics within public discourse, especially when reported in the media. For him, epigenetics is: 'always kind of tabloid news. I think that our, it's our grandfather is responsible for our obesity or, the, the kind of story that's, er, which amuse people more than really is important for science.' Distaste was expressed too by Respondent 6 over some of the ways the term 'epigenetics' had come to circulate beyond biomedicine, and in particular the claims that adhered to it:

So the problem is, I mean, you may have seen this, I don't know where, if you started going to that area where you get that boundary between science, and I have to say nonscience, you start to find people, they're very clever, they're very intuitive, they want to find things in, but they go off into areas of the internet that I wouldn't want to really delve in, almost from the point of view of contaminating myself, but, you know, you end up with these people like, which are lifestyle coaches, who are going to make you a better person by changing your epigenetic profile. Eat a lot of cabbage or something, I don't know. And, you know, they're just charlatans. They're just snake oil salesmen, who are just selling you a ridiculous idea.

Regardless of such concerns, however, the respondents were generally positive about communicating their research to an audience outside of bioscience; Respondent 1 , for instance, stated that he enjoyed public engagement, and especially trying to "convey some of the excitement that is coming out of science at the moment'. Yet, this was not a set of activities that the scientists I interviewed were very regularly involved with - although Respondent 7's sentiments that he was 'increasingly aware that I should do!' seemed shared across the sample. For those who had participated in science communication and engagement events, involvement was generally somewhat recent, and occasionally linked to funder requests; for example, Respondent 5 noted that much of his work had been sponsored by one large charity and he felt that 'I do owe them'.

Respondents 2 and 4 both reflected on the necessity of communicating explicitly about epigenetics. In the words of the latter:

I think firstly it's a growing field of science, clearly. And so then therefore you know it's important that the public knows, because part of their tax money goes to funding 
epigenetics, so I think they should know about it. I think that they should experience if they can the same excitement of new knowledge that's being created that we are excited about. Because it really, in my opinion, enriches humankind to have new knowledge. Just as simple as that. So I think that's really important. And-and I think also as dogma gets replaced by other dogma, the genome has had a stranglehold for a long time and I think it's important to show that there's other views of biology, selection, inheritance which are emerging that give you different ways of thinking about Mendel and Darwin et cetera. And finally there is hope for treatments, but that hope is very early. So you probably know that there is epigenetic drugs in the clinic. They show some promise. They are very unspecific. [...] But there are strategies for going into the epigenome in a much more focused and targeted way to change it. And I think that's also important, that people get to know about that even if it's very early days and we can't tell them, well, we're going to cure this disease and that disease with these approaches. So I think to me at multiple levels, it's, it's good for the public to know about it.

Respondent 4 was also reflective about the ambiguous position of scientists simultaneously positioning epigenetics as exciting and important, while also noting its associated uncertainties:

I'm very excited about epigenetics and the potential that it has. But I'm also very conscious that it gets overhyped and there are scientists that are less cautious in portraying it out there. And my personal view of that is that that's, er ... I wouldn't say not the right thing to do, because there's this balance of actually bringing it to the attention of the public, which is important. And how do you do that without overhyping it? I don't know, because people want stories, you know, people, people pick up stories and they want to relate to their own lives.

He felt that 'we probably need a mixture of voices to the public, since 'it's not a thing that is a scientific fact, that the scientific community agrees on'. In effect, Respondent 4 indicates the challenges of scientists working within regimes both of hope and of truth (Moreira and Palladino, 2005) - challenges that are made more acute by the very real hopes expressed by some of the publics with whom he had communicated. Reflecting on an event at which he had recently spoken, Respondent 4 suggested:

the underlying emotion there I think is that people are excited about this possibility that they're not not only slaves of the genome, that they could influence by whatever magic potion the epigenome, and therefore alter and potentially undo things that have happened to their epigenome in the past. And therefore better their lives with this magic potion that we're supposed to come up at some point with! [laughs]

When I asked how he responded to this, Respondent 4 replied:

So I think that, um, I guess my response is that, these are the scientific facts that we have now, there is clearly some ideas, experiments and evidence that nutrition and environment can influence epigenetics. But this is so diffuse in terms of identifying the specific factors and the underlying mechanisms, that at this point there is absolutely no specific advice that we can give to people on what they should be doing, or should not be doing, that, that could, that could help with this. And this then comes as a disappointment to people obviously. 
Respondent 8 felt that he had to act as one such moderating voice at a public engagement event he'd participated in. He described the difficulties of punctuating hype whilst galvanising enthusiasm in science more broadly:

And then, so my problem is, that the idea that your environment determines what you pass on to your offspring, or er has a long-term effect on you, via your genes in this way, is actually quite interesting and exciting and erm novel. And my problem is, I have to spend my time saying why it might not be that simple, so I come across as a little bit of a curmudgeon, who kind of, erm er, you know perhaps a grumpy old man, who wants people to see that biology is interesting, despite the fact that this stuff may not be correct. And that doesn't always work. It's more difficult anyway.

These data underscore the affective responses of scientists to their research (Keller, 1983; Koppman et al., 2015; Pickersgill, 2012), made manifest especially with regards to the concerns of some respondents that biological findings and concepts are being communicated 'inappropriately'. Such emotion seems to speak to deep, decades-long commitment to research, and to scientists' roles as, ultimately, seekers of biomedical truth. My respondents, I suggest, care about the production of knowledge, about the enthusiasm that this can stimulate in non-scientists, and about the importance of precision in communicating developments in the biosciences to those without sufficient expertise themselves to adjudicate new claims. Such care(-work) generates ambivalence in some cases about public engagement with epigenetics, given the need for scientists working in this area to navigate enjoinders to communicate with both modesty and ostentation (cf. Moreria and Palladino, 2005). This ambivalence is in part a consequence of the uncertainties and ambiguities around epigenetics highlighted by the respondents (to a greater or lesser extent). Expanding societal understanding of and excitement regarding science was taken to be a social good, but the proliferation of 'alien science' (Collins, 1999; Hedgecoe, 2006) which was itself fed by public fervour was deemed concerning. The texture of this concern did not appear to be constituted through self-interest regarding the ways such (apparently misplaced) enthusiasms might shape funding pathways and research trajectories. Rather, concern looked to be an articulation of empathetic citizenship within which false hopes and expectations on the part of non-scientists were to be lamented and, where possible, minimized - especially when they might come to shape policy directives and the lives of the people they target.

\section{Discussion}

We can see that there is a lack of consensus within bioscience over the meaning of epigenetic effects, mechanisms, and even the word itself. There are (affective) corollaries to such ambiguities when scientists communicate with their peers and with wider publics, particularly regarding the contested topic of transgenerational inheritance. ${ }^{8}$ Yet, in spite of professed uncertainties, and evident disagreement around the meanings and nature of epigenetic processes, scientists are hardly paralysed; indeed, my interviewees were selected precisely because 
of their energetic research activity. Accordingly, this study underscores a point made by Rheinberger (2010) and others (Lloyd and Raikel, 2014a; Pickersgill, 2014): specifically, conceptual lability and instability do not necessarily impede biomedical innovation, but can instead drive it forward. As various ambiguities endure and disagreements proliferate, a range of research trajectories are undertaken in response; hence, uncertainty is part of the knowledge machinery of scientific practice (cf. Moreira et al., 2009). Such uncertainty relates not simply to 'what is (un)known' about the biological world, but more importantly refers to potentially more intractable questions regarding the accepted theoretical and material starting points for addressing this issue.

Frank admissions of uncertainty, ambiguity and opacity can be taken as an instantiation of 'epistemic modesty' (cf. Will, 2010). Catherine Will has described the rhetorical effectiveness of 'gestures of therapeutic and epistemic modesty' (Will, 2010: 547) within clinical texts as a means of galvanizing support for research. In employing the term 'epistemic modesty' here, I take seriously the idea that reflexive awareness of the limits of scientific knowledge is one of the 'operative norms of performance' (Freidson, 1970: 160) in the life sciences. It is precisely because of this, I suggest, that expressions of modesty are an effective strategy by which to communicate scientific professionalism, render problematic the research of competitors, and propel innovation. In turn, the instrumental uses to which the rhetoric of modesty can be put further embed its (reciprocally) constitutive role in biomedical practice.

The relationship of an ethos of epistemic modesty to an ethic of scientific professionalism renders more legible the sometimes strongly worded concerns of my respondents around the communication of epigenetics to non-scientists. In particular, the controversial notion of transgenerational inheritance was sometimes configured as a kind of 'alien science' (Collins, 1999; Hedgecoe, 2006) - that is, knowledge often deemed deficient in facticity to subject specialists, but highly compelling to those adjacent to or acquainted with the field. This 'alien science' occasionally provoked ire, frustration or exasperation in respondents as they reflected on the communication practices of other researchers. Some unease about public discussion of epigenetics more generally was also evident in the interview accounts; for example, because it might (over-)inflate hopes and expectations.

These emotions, I suggest, respond to the performance of a perceived immodesty by other scientists. In other words, a will to speak modestly is generative of affect when an inappropriate failure to do so is noted elsewhere. This occurs even as wider expectations to boldly articulate one's professional and scientific achievements continue to increase. That these expectations are so strikingly apparent within universities, and immodestly allowed (indeed, encouraged) in various contexts, implies two interlocking 'regimes' of scientific praxis (cf. Moreira and Palladino, 2005). First, a regime of epistemic modesty; second, a regime of what we might term 'epistemic ostentatiousness' - namely, a rather more flamboyant display of scientific knowledge that while not deceitful nevertheless presents the 'best side' of research and of researchers to a range of audiences. Part of being a 'responsible' scientist, it seems, is to know when, in both public and professionals 
forums, to adopt the appropriate register of modesty or ostentation - a trick that relates to the wider scientific consensus on the epistemic domain in question.

The scientific uncertainties and discomfort with epistemic ostentatiousness documented here are pertinent to social scientists, who have become 'excited' (Niewöhner, 2011: 280) about epigenetics, and especially transgenerational inheritance. Such excitement is a significant affective aspect of the knowledge machinery of the social sciences, and the efforts of scholars to theorize with and through epigenetics. Tolwinkski has reflected that assumptions can sometimes be made that a 'fundamental and paradigmatic change' is taking place within the biosciences regarding epigenetics (Tolwinski, 2013: 382). However, as she has documented for the US, and I have shown in the UK, this assumption might not bear out. While the epistemic modesty of my respondents may partly reflect attempts to position themselves as certain kinds of (responsible) scientists, their emotional responses to perceived ostentation in others' claims-making (in both scientific and public forums) further points to dissensus in the biosciences regarding epigenetics. This corresponds too with the careful caveats that circulate within scientific texts in this area (Pickersgill et al., 2013). If anything characterizes research on epigenetic marks and mechanisms, it is perhaps a reflective lack of consensus on the nature and biological significance of the processes under examinations.

As scholars in sociology, anthropology and elsewhere are engaging increasingly with epigenetics research, they are implicitly (and sometimes explicitly) weighing the claims of life scientists. Accordingly, social scientists themselves come to contribute to 'deciding the [assumed] character' of biological processes and ontologies (cf. Collins, 1975: 220), within the academy and beyond. Such a contribution might not be considered problematic to scholars seeking to 're-vitalize' (Rose, 2013) the social sciences, and work in a more collaborative fashion with bioscientists. However, given enthusiasm for transgenerational inheritance, and bioscientific uncertainty regarding precisely this matter, the potential exists for sociologists to co-produce an 'alien science' that may disaffect the very communities of life scientists with which scholars are seeking to collaborate. Moreover, though collaboration with biologists has been described as a way to move 'beyond description, commentary and critique' (Rose, 2013: 23), the idiom of 'beyond' implies an epistemological hierarchy which seems unlikely to be helpful to social scientific collaborators of life scientists. Finally, those energized by such possibilities have sometimes articulated these through a rather ideational register. Yet, sociological fashion - as the work of sociologists of fashion reminds us (Mears, 2011) - relates closely to perceptions of economic value and processes of valuation. Within biomedicine, money 'carves deep interdisciplinary tracks' (Rapp, 2011: 673), and the different kinds of capital available to social scientists wanting to engage with epigenetics could be significant. This issue invites further reflection on behalf of sociologists regarding the incorporation of bioscientific claims within their own knowledge machinery. 


\section{Conclusion}

This paper has documented some of the various contestations and uncertainties in epigenetics (centring especially on transgenerational inheritance), and the concerns scientists have about the communication of research in this area. As biology and sociology potentially move closer into alignment, the allure of the former comes to be part of the knowledge machinery of the latter. This certainly does not preclude (open-mindedness towards) new relationships between the life and social sciences (Landecker and Panofsky, 2013; Lock, 2015; Pickersgill et al., 2013). Yet, scientific research articulated through a regime of epistemic modesty is perhaps less attractive to social scientists than that situated in a regime of epistemic ostentatiousness, with ramifications for (continued) collaboration with bioscientists working in epigenetics.

\section{Acknowledgements}

I am very grateful to the Wellcome Trust for supporting this study (grant number: WT103917FR), as well as to the scientists who generously agreed to participate in it. I would like to thank the issue editors, the anonymous reviewers, and Tineke Broer for thoughtful commentaries on earlier versions of this article.

\section{Notes}

1 The sampling strategy appears to have been successful, in terms of interviewing notable scientists, since some respondents recommended as potential interviewees individuals that I had already approached.

2 The shortest interview took place over the phone; all others took place in the participants' offices.

3 All italicizations within quotes reflects the emphasis in the participants' talk.

4 Specifically, in relation to the possibilities of transgenerational inheritance in animals. The scientists seemed comfortable with the notion that this process had been clearly established in plants.

5 Respondent 3 also had strong words on where studies evidencing transgenerational inheritance were published, dismissing one key journal as a 'tabloid'.

6 Some of the uncertainties in epigenetics, and transgenerational inheritance especially, have also been flagged by Landecker and Panofsky, 2013; Lloyd and Raikel, 2014b; Lock, 2015; Meloni and Testa, 2014; Niewöhner, 2011; and Tolwinski, 2013.

7 Here, Respondent 8 is implicitly referencing my study Participant Information Sheet and the opening interview preamble, both of which noted that my research sought to 'understand what social and ethical issues scientists working in epigenetics judge to be important'.

8 Evidence for these points comes from interviews with key scientists, but the issues highlighted are apparent across editorials, review articles and research papers in bioscientific journals (see also Tolwinski, 2013).

\section{References}

Barnes, B. and Dupré, J., (2008), Genomes and What to Make of Them, Chicago: Chicago University Press.

Collins, H. M., (1975), 'The seven sexes: a study in the sociology of a phenomenon, or the replication of experiments in physics', Sociology, 9 (2): 205-224. 
Collins, H. M., (1999), 'Tantalus and the aliens: publications, audiences and the search for gravitational waves', Social Studies of Science, 29 (2): 163-197.

Feyerabend, P., (2011), The Tyranny of Science, Cambridge: Polity Press.

Fitzgerald, D. and Callard, F., (2014), 'Social science and neuroscience beyond interdisciplinarity: experimental entanglements', Theory, Culture \& Society, 32 (1): 3-32.

Freidson, E., (1970), Profession of Medicine: A Study of the Sociology of Applied Knowledge, Chicago: University of Chicago Press.

Hedgecoe, A., (2006), 'Pharmacogenetics as alien science: Alzheimer's' Disease, core sets and expectations', Social Studies of Science, 36 (5): 723-752.

Keller, E. F., (1983) A Feeling for the Organism: The Life and Work of Barbara McClintock, San Francisco: Freeman.

Koppman, S., Cain, C. L. and Leahey, E., (2015), 'The joy of science: disciplinary diversity in emotional accounts', Science, Technology \& Human Values, 40 (1): 30-70.

Landecker, H. and Panofsky, A., (2013), 'From social structure to gene regulation, and back: a critical introduction to environmental epigenetics for sociology', Annual Review of Sociology, 39: 333-357.

Lloyd, S. and Raikel, E., (2014a), 'Uncertain objects in the molecular epigenetics of suicide', paper presented at the 2014 Annual Meeting of the American Anthropological Association, Washington DC, 4 December.

Lloyd, S. and Raikel, E., (2014b), 'L'épigénétique environnementale et le risque suicidaire: Reconsidérer la notion de contexte dans un style de raisonnement émergent', Anthropologie \& Santé, 9: $2-19$.

Lock, M., (2015), 'Comprehending the body in the era of the epigenome', Current Anthropology, 56 (2): $151-177$.

McGowan, P. O., Sasaki, A., D’Alessio, A. C., Dymov, S., Labonté, B., Szyf, M., Turecki, G. and Meany, M. J., (2009), 'Epigenetic regulation of the glucocorticoid receptor in human brain associates with childhood abuse', Nature Neuroscience, 12 (3): 342-348.

McGowan, P. O., and Szyf, M., (2010), 'The epigenetics of social adversity in early life: implications for mental health outcomes', Neurobiology of Disease, 39 (1): 66-72.

Mears, A., (2011), Pricing Beauty: The Making of a Fashion Model, Chicago: Chicago University Press.

Meloni, M., (2014), 'How biology became social, and what it means for social theory', Sociological Review, 32: 593-614.

Meloni, M., and Testa, G., (2014), 'Scrutinizing the epigenetics revolution', BioSocieties, 9 (4): 431-456.

Moreira, T. and Palladino, P., (2005), 'Between truth and hope: Parkinson's Disease, neural transplants and the self', History of the Human Sciences, 3: 55-82.

Moreira, T., May, C. and Bond, J., (2009), 'Regulatory objectivity in action: mild cognitive impairment and the collective production of uncertainty', Social Studies of Science, 39: 665-690.

Nicolosi, G. and Ruivenkamp, G., (2012), 'The epigenetic turn: some notes about the epistemological change of perspective in biosciences', Medicine, Health Care and Philosophy, 15: 309-319.

Niewöhner, J., (2011), 'Epigenetics: embedded bodies and the molecularisation of biography and milieu', BioSocieties, 6 (3): 279-298.

Pickersgill, M., (2012), 'The co-production of science, ethics, and emotion', Science, Technology \& Human Values, 37 (6): 579-603.

Pickersgill, M., (2014), 'The endurance of uncertainty: antisociality and ontological anarchy in British psychiatry, 1950-2010’, Science in Context, 27 (1): 143-175.

Pickersgill, M., Niewöhner, J., Müller, R., Martin, P. and Cunningham-Burley, S., (2013), 'Mapping the new molecular landscape: social dimensions of epigenetics', New Genetics and Society, 32: 429-447.

Rapp, R., (2011), 'Chasing science: children's brains, scientific inquiries, and family labors', Science, Technology and Human Values, 36 (5): 662-684. 
Rheinberger, H-J., (2010), An Epistemology of the Concrete: Twentieth-Century Histories of Life, Durham, NC: Duke University Press.

Rose, N., (2013), 'The human sciences in a biological age', Theory, Culture and Society, 30 (1): $3-34$.

Star, S. L., (1985) 'Scientific work and uncertainty', Social Studies of Science, 15 (3): 391-427.

Tolwinski, K., (2013), 'A new genetics or an epiphenomenon? Variations in the discourse of epigenetics researchers?', New Genetics and Society, 32 (4): 366-384.

Weaver, I. C. G., Cervoni, N., Champagne, F. A, D’Alessio, A. C., Sharma, S., Seckl, J. R., Dymov, S., Szyf, M. and Meaney, M. J., (2004), 'Epigenetics programming by maternal behavior', Nature Neuroscience, 7 (8): 847-854.

Will, C. (2010), 'The management of enthusiasm: motives and expectations in cardiovascular medicine', Health, 14 (6): 547-563.

Please quote the article DOI when citing SR content, including monographs. Article DOIs and "How to Cite" information can be found alongside the online version of each article within Wiley Online Library. All articles published within the SR (including monograph content) are included within the ISI Journal Citation Reports ${ }^{\circledR}$ Social Science Citation Index. 